\title{
María Montessori y la educación cósmica
}

\author{
Juan José Morales Ruiz
}

Doctor en Ciencias de la Información por la Universitat Autònoma de Barcelona. Profesor del Master de Historia de la Masonería en España y América en la Universidad Nacional de Educación a Distancia (UNED), España. Correo electrónico: jmorales@,calatayud.uned.es

DOI: http://dx.doi.org/10.15517/rehmlac.v7i2.22697

Fecha de recibido: 6 de octubre de 2015 - Fecha de aceptación: 20 de noviembre de 2015

\section{Palabras claves}

La mente absorbente, el embrión espiritual, educación cósmica, teosofía, guerra y paz, las potencialidades humanas, ciudadana del mundo, Casa dei Bambini

\section{Keywords}

The Absorbent Mind, the spiritual embryo, Cosmic Education, Theosophy, War and Peace, 1 human potential, Citizen of the World, Children's House

\begin{abstract}
Resumen
La etapa de Montessori en la India fue uno de los periodos más enriquecedores en la vida de Maria Montessori. Allí escribió y publicó La Mente Absorbente del niño, y una serie de libros fundamentales. En su obra La educación de las potencialidades humanas desarrolló los principios de la "Educación Cósmica" que adaptó para el currículo de Primaria. Invitada en 1939 a dar unas conferencias en la India por el Presidente de la Sociedad Teosófica, Montessori y su hijo, se vieron atrapados por el estallido de la Segunda Guerra Mundial, y su posterior desarrollo. Tenía 69 años cuando llegó a Madrás. Permaneció diez años. Pero nada sería igual que antes. Había una Montessori antes de la India, y otra mucho más profunda después. Cuando regresaba a Europa declaró, a los que le preguntaban qué había hecho en la India: "creo que he aprendido a aprender, como el Niño".
\end{abstract}

\begin{abstract}
The decade Maria Montessori spent in India was one of the most enriching periods of her life. During that phase, she wrote and published The Absorbent Mind Of The Child, as well as a number of fundamental books in her career. In The Education of Human Potentialities, she developed the principles of the "Cosmic Education", a curriculum which she adapted for elementary students. Invited in 1939 to give lectures by the president of the Theosophical Society, Maria Montessori and her son were trapped by the outbreak of World War II and its subsequent development. She was 69 when she arrived to madras. She stayed ten years. There was a Maria Montessori before India, and a much deeper one later. When she returned to Europe, when asked what she had done in India, she declared, "I think I've learned how to learn, as if I were a Child".
\end{abstract}

\section{Introducción}

Para María Montessori, los años vividos en la India serán una ocasión privilegiada para enseñar, pero también para profundizar y elaborar un "concepto cósmico" de 
Educación que contemplará a los hombres como seres interrelacionados con la Naturaleza, de acuerdo con un plan a escala universal y cósmica ${ }^{1}$.

$Y$, en este sentido, los principios teosóficos ${ }^{2}$ podían representar un ambiente ecuménico, adogmático y tolerante, muy próximo al pensamiento filosófico de María Montessori. Los ideales que defendía la Teosofía coincidían con sus anhelos de formar una hermandad universal, en la que toda la humanidad, sin distinción de raza, credos, sexos, castas, ni colores, pudiera construir una nueva sociedad más humana y más justa ${ }^{3}$.

Objetivos muy lejos de conseguirse, en un mundo terriblemente azotado por la guerra y la destrucción. María Montessori defendía que había que potenciar los estudios sobre las diversas religiones, las filosofías y las ciencias. Y, por último, pero muy importante, creía que había investigar las leyes todavía inexploradas de la Naturaleza y, sobre todo, las inmensas potencialidades del hombre.

\section{La Sociedad Teosófica}

Montessori se asoció a la sección europea de la Sociedad Teosófica en Roma, el 23 de mayo de $1899^{4}$. Tenía 29 años. Unos años después asistió a una conferencia de Annie Besant en Londres, en 1907. Annie Besant hizo un elogio de la obra de Montessori sellando desde entonces una profunda amistad. Pero tendrían que pasar uno años, hasta que se produjera una nueva conexión con la Teosofía.

Fue en noviembre de 1939, apenas dos meses después del inicio de la Segunda Guerra Mundial, cuando María Montessori y su hijo Mario viajaron a la India, alejándose de una "Europa en llamas", invitados por George Sidney Arundale, Presidente de la Sociedad Teosófica, Gran Comendador de la organización masónica "Le Droit Humain” y rector de la Banaras Hindu University ${ }^{5}$.

\footnotetext{
${ }^{1}$ Mary Hayes, "Montessori's View of Cosmic Education" (ponencia presentada en el International Montessori Congres, Sydney, Australia, 14-17 July 2005).

${ }^{2}$ La Sociedad Teosófica fue fundada en 1875. Es una organización cuyo primer objetivo es la Fraternidad Universal. La Sociedad no impone ningún tipo de creencias. Sus miembros están unidos por la búsqueda de la Verdad. Los fundadores de la Sociedad Teosófica fueron H. P. Blavatsky y H. S. Olcott, que fue presidente vitalicio. Annie Besant, segunda presidenta de la Sociedad Teosófica, fu ampliamente conocida por sus escritos, discursos y por sus actividades políticas llevadas a cabo en la India, en pro de reformas sociales. George Sydney Arundale (1878-1945) fue el tercer Presidente de 1934 a 1945.

${ }^{3}$ Giacomo Cives, "María Montessori tra scienza, spiritualità e laicità", Studi sulla formazione 2 (2014): 119147 y Renato Foschi, María Montessori (Barcelona: Octaedro, 2014), 103.

${ }^{4}$ El primer carnet de María Montessori fue descubierto recientemente en los Archivos de Adyar (India), sede central de la Sociedad Teosófica.

${ }^{5}$ María Montessori habría pedido asilo en Colombia dada la gravedad de la situación internacional, pero las gestiones se retrasaban y, entre tanto, surgió afortunadamente la posibilidad de viajar a la India. En el Centro de Documentación Agustín Nieto Caballero hay documentación sobre la demanda de asilo.
} 
Arundale había conocido a Montessori en una visita a Londres, realizada en el año 1934, y a partir de ese encuentro surgió una gran amistad. María Montessori le dedicó uno de sus libros publicados en la etapa india: Educar para un nuevo mundo ${ }^{6}$.

Imagen 1

María Montessori y George Sidney Arundale, Presidente de la Sociedad Teosófica en Adyar, India

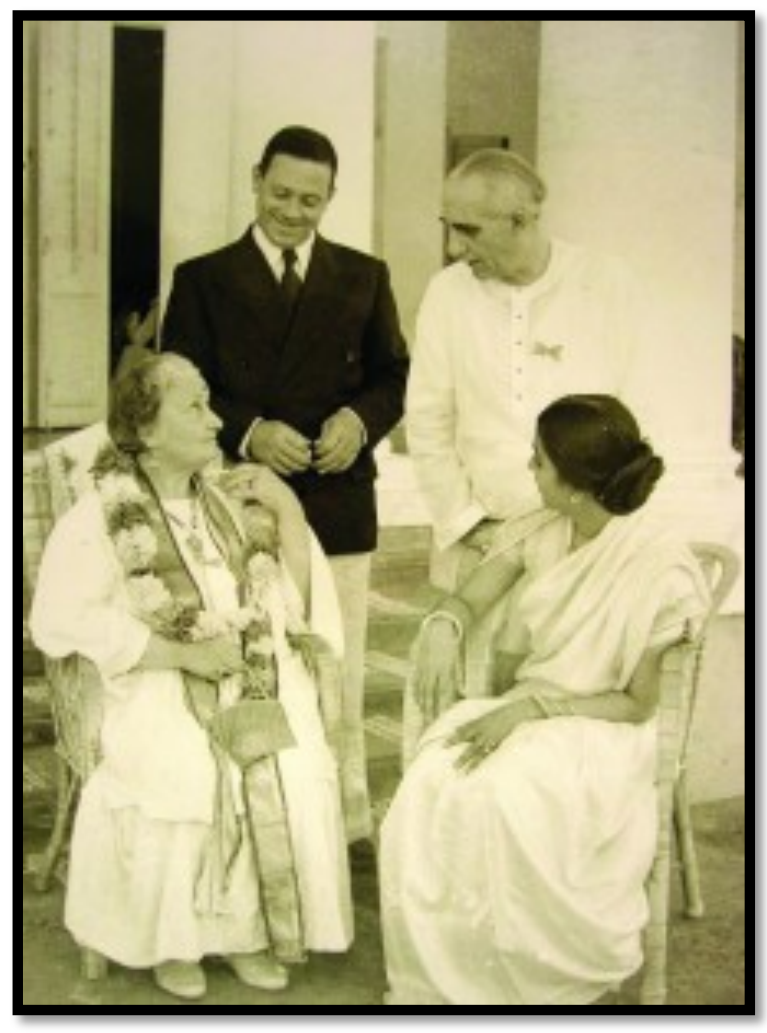

Fuente: Archivo de la Sociedad Teosófica en Adyar, India.

Estando en la India, le sorprende el estallido de la Segunda Guerra Mundial. A pesar de su nacionalidad italiana,- Italia era "aliada" de la Alemania nazi y por lo tanto "enemiga" de Gran Bretaña -, podrá continuar su tarea docente, pero su hijo Mario será internado en un campo de concentración. Como "regalo de cumpleaños" (Montessori cumple 70 años) el Virrey de la India le anuncia la puesta en libertad de su hijo ${ }^{7}$.

Ambos regresarán a Europa al cabo de diez años al final de la segunda guerra mundial, permaneciendo durante un primer tiempo en el cuartel general de la Sociedad

\footnotetext{
${ }^{6}$ María Montessori, Educar para un nuevo mundo (Ámsterdam: Montessori-Pierson Publishing Company, 2014). El libro de María Montessori lleva la siguiente dedicatoria: "Dedicado a la memoria de George Sidney Arundale, quien me invitó a la India y me brindó la oportunidad de conocer ese maravilloso país, y de ponerme en contacto con él y su gran personalidad".

${ }^{7}$ Juan José Morales Ruiz y Luis Jorge García Dueñas, María Montessori (Madrid: Ed. Fundación Emmanuel Mounier, 2009), 32.
} 
Teosófica en Adyar, y más tarde en Kodaikanal, una zona de más altura y un clima más suave. Y precisamente en Kodaikanal María Montessori irá publicando los libros más importantes que permiten profundizar en la filosofía y el Método pedagógico que lleva su nombre.

Imagen 2

María Montessori con su hijo Mario en Adyar, India

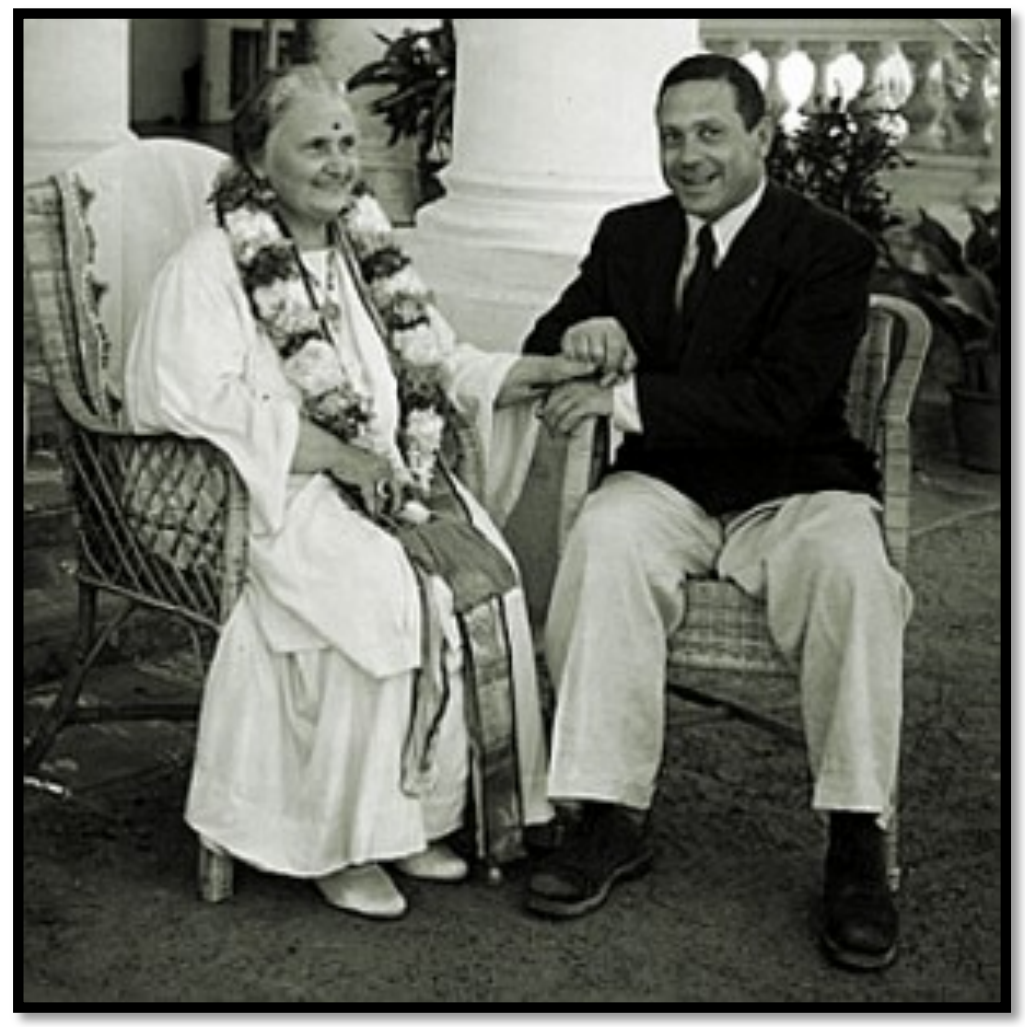

Fuente: Archivo de la Sociedad Teosófica en Adyar, India.

En la India, publicará los siguientes libros: The Discovery of the Child (1948); Education for a New World (1947); To Educate the Human Potential (1947); The Formation of Man (1949); y The Absorbent Mind (1947). Y en Colombo (Sri Lanka): Wat You Should Know about Your Child (1948).

De hecho, hasta su fallecimiento el 6 de mayo de 1952, en la ciudad holandesa de Noordwijck am See, en cuyo cementerio está enterrada, Montessori estuvo relacionada con el ambiente teosófico internacional.

Relaciones que a principios del siglo XX eran muy intensas con la teosofía romana, como demuestra su amistad con Francesco Randone (1864-1935), escultor, teósofo, masón 
fundador de una escuela de pintura, cuyas teorías y métodos pedagógicos, fueron comentadas en la primera edición del Método ${ }^{8}$.

\section{La Educación Cósmica}

En su libro "Educación de las potencialidades humanas" Montessori desarrolla su visión sobre la Educación Cósmica. Por ejemplo en el capítulo titulado El niño de seis años y el Plan Cósmico ${ }^{9}$, María Montessori afirma que

(...) la educación entre los seis y los doce años no es una continuación de la etapa anterior, pero se basa en dicha etapa. Dice que "en lo psicológico, cambia decididamente la personalidad, y conforme lo ha determinado la naturaleza, durante este periodo el niño adquiere todo cuanto tiene que ver con la cultura (...)

La conciencia, que ha tenido ya un considerable desarrollo, ahora sale en una dirección determinada, la inteligencia se vierte al exterior y el niño muestra una predisposición a indagar la razón de las cosas como nunca lo había hecho (...) En esta etapa se siembra la semilla de todo, pues la mente del niño es similar a un suelo fértil dispuesto a acoger lo que más adelante germinará (...) Pero si en este periodo especial la mente no recibe la atención suficiente o no logar satisfacer sus necesidades vitales, termina por atrofiarse.

El niño tiene que aprender de su propia actividad. Hay que darle lo que necesita y no hacerle ningún cuestionamiento con respecto a su elección. La enseñanza se debe limitar a satisfacer las demandas mentales, nunca dictarlas.

Los niños pequeños no se pueden mantener quietos porque necesitan coordinar sus movimientos. Del mismo modo, quizá los más grandes parezcan un poco problemáticos cuando indagan acerca de qué, cómo y por qué de todo lo que ven, pero lo hacen porque están construyendo su intelecto mediante la actividad mental, y es imperativo alimentar ese intelecto en amplios campos de la cultura.

Enseñar se convierte en una tarea fácil, puesto que no es necesario elegir qué es lo que hay que darle al niño, basta con ponerle todo al alcance de las manos para que satisfaga su apetito mental. El niño requiere absoluta libertad de elección, y luego bastará con que repita las experiencias varias veces, y cada vez pondrá un interés más marcado y una mayor concentración para adquirir el conocimiento deseado.

El niño de seis años que ha estudiado en una escuela Montessori tiene la ventaja de tener más conocimientos que el que no ha vivido esta experiencia Sabe leer y escribir, se interesa por las matemáticas, la ciencia, la geografía y la historia, y entonces resulta más fácil iniciarlo en otros conocimientos, por vastos que estos sean.

\footnotetext{
${ }^{8}$ Foschi, María Montessori, 33-35.

${ }^{9}$ Montessori, La Educación de las potencialidades humanas (Ámsterdam: Pierson-Publishing Company, 2015), 4- 23.
} 
El educador se encuentra frente a un individuo que ya ha adquirido la base de la cultura y está deseoso de edificar sobre estos cimientos, de aprender y penetrar hasta lo más profundo de cualquier tópico. ¡Qué llano se le presenta entonces el camino al educador! ¡Hasta parecería que no tuviera que hacer nada! Pero no, la labor del educador no es nada fácil, ni pequeña.

Tiene que contar con una cantidad colosal de conocimientos para saciar el hambre mental del niño y, a diferencia de un maestro tradicional, no cuenta con ningún programa que le limite y le diga qué es lo que debe enseñar de cada materia, sin excederse jamás en una determinada cantidad de tiempo. Está claro que las necesidades del niño son más difíciles de satisfacer y cada vez se hace más inaceptable que el educador se refugie en la rutina de los programas y los horarios $(\ldots)$

\section{Una visión de todo el Universo}

María Montessori cree que

(...) ya que hay que brindarle tanto al niño, démosle una visión de todo el Universo. El Universo es una realidad imponente, una respuesta a todas las preguntas. Debemos andar juntos este camino, pues todas las cosas son parte del Universo y están conectadas entre sí para formar una completa unidad. (...)

Es necesario centralizar los intereses del niño, pero los métodos comunes no logran cumplir ese objetivo ¿Cómo es posible mantener interesada la mente de un individuo en crecimiento, si todo lo que le enseñamos gira en torno de un mismo y limitado tema particular y sólo se podrán transmitir los detalles ínfimos que es capaz de memorizar? ¿Cómo vamos a forzar al niño a que se interese por algo, si el único interés auténtico es el que surge de su interior? Lo que se impone desde fuera no es otra cosa que obligación y esfuerzo fatigoso, ¡nunca el verdadero interés! Esto debe quedar bien claro.

Si la idea del Universo se presenta ante el niño en la forma adecuada, se logrará algo más que despertar su interés, pues ella le causará admiración y asombro, sentimientos más elevados y gratificantes que cualquier otro tipo de interés. La mente del niño ya no se perderá sin rumbo, se fijará en un determinado foco. Así, los conocimientos que adquiere se vuelven organizados y sistemáticos. La inteligencia se manifiesta como una totalidad gracias a la visión completa que se le ha presentado, y el niño se interesa por todo, pues cada cosa está interconectada con las demás y ocupa un sitio en el universo en el cual se centra su mente.

\section{¿Qué soy yo?}

Las estrellas, la Tierra, las piedras, todo tipo de vida conforma una totalidad en su relación con lo demás, una relación tan estrecha que sería imposible comprender la naturaleza de una piedra... ¡sin antes comprender el inmenso Sol! No importa qué es lo que tocamos, si es un átomo o una célula, es imposible explicarlo sin conocer el ancho universo. ¿Existe alguna respuesta mejor que les podamos dar 
a esos buscadores de conocimientos? Incluso cabría preguntarse si será suficiente con el universo... ¿Cómo nació? ¿Cómo llegará a su fin?

Estas dudas son parte de una curiosidad aún mayor que, una vez surgida, jamás en la vida entera podrá ser saciada. Es posible hacer que las leyes que gobiernan el universo se presenten ante el niño como algo interesante y maravilloso, aún más que los objetos mismos. Entonces el niño empieza a hacer preguntas: ¿Qué soy yo? ¿Cuál es la tarea del hombre en este maravilloso universo? ¿Estamos aquí sólo con la función de vivir para nosotros mismos o tenemos otra función? ¿Por qué peleamos y luchamos? ¿Qué es el bien y el mal? ¿En qué terminará todo?

Este plan de Educación Cósmica, -concluye-, piedra fundamental del Método Avanzado, se expuso por primera vez en Inglaterra, en 1935, y demostró ser el único camino posible para proseguir con paso firme las investigaciones en materia educativa. Se hace imposible utilizarlo con niños analfabetos o completamente ignorantes, pero los que han recibido la preparación indirecta a través del Método Montessori lo aceptan con entusiasmo.

\section{Un Dios sin manos}

Los descubrimientos de los hombres inteligentes,- escribe María Montessori -, fueron lo único que nos permitió reconstruir en la imaginación la historia del planeta y sus seres vivientes. Y tales descubrimientos no fueron obra de una inteligencia aislada sino que contaron con el apoyo de la ciencia sistemática. El hombre culto actual es superior al hombre natural porque está dotado de instrumentos de gran potencia $^{10}$.

Cuenta con el microscopio y el telescopio para extender su visión, y con los conocimientos acumulados de los matemáticos, químicos y físicos que, gracias a esos poderes mágicos de la mente humana, investigaron los secretos de la naturaleza. Así aparee la grandeza del hombre, un agente creativo y transformador que se sitúa por encima de los animales o las plantas, un explorador del mundo entero y del universo que lo rodea, capaz incluso de regresar en el tiempo y explorar lo que ha dejado de existir hace años.

Todos los temas que estudiamos y nos interesan se pueden relacionar con millones de hombres que han trabajado arduamente, a veces pasando hambre, con tal de superar los obstáculos que se presentaron a su comprensión, para que el acceso al conocimiento no nos costara tanto como a ellos. Todo es fruto del alma humana, y la recolección de estos frutos, tesoro millonario que nos ha legado el hombre, se encarna en la educación.

Tenemos que admirar a todos los pioneros, conocidos o no, poseedores de la llama que ha alumbrado el sendero de la humanidad, e inspirar en los niños esa misma admiración. A la mayoría de la gente le cuesta interesarse por las novedades; incluso los intelectuales progresan muy lento en la esfera del pensamiento, pues son hostiles a las ideas de nuevas que representan una amenaza para la seguridad mutua.

\footnotetext{
${ }^{10}$ Montessori, La Educación de las potencialidades humanas, 56-60.
} 
La gente es perezosa física y mentalmente, sólo quiere disfrutar la vida. Eso genera más admiración aún hacia quienes son diferentes, quienes sienten una fuerza interior que los impulsa a actuar en contra de su propio bienestar y felicidad, aún a riesgo de su vida $(. .$.

Pero no admiramos a estos aventureros del pasado y el presente para reconfortarlos con nuestra gratitud, pues no les va a llegar. Queremos que el niño comprenda el papel que ha cumplido la humanidad y todo lo que aún le queda por hacer, y que de ese modo conseguirá la elevación del alma y la conciencia moral. La historia debe de ser algo vivo y dinámico, capaz de incentivar el entusiasmo y destruir el egoísmo intelectual la pereza individualista (...)

La historia de los logros del hombre es algo real; un testigo vivo de la grandeza humana, y los niños se estremecen con facilidad solo de pensar que millones de personas como ellos están haciendo todo tipo de esfuerzos físicos y mentales para resolver los problemas de la vida, y que todos contribuyen para hallar la solución, aunque tal vez sea uno el que la encuentre.

Al igual que con las eras geológicas, el medio tiene que estar preparado para recibir ideas nuevas que se avecinan. Cuando el pensamiento está preparado, basta con que se organicen muchas mentes en una atmósfera intelectual adecuada para que surjan los descubrimientos. Cientos de pensamientos se cristalizan en un solo hombre, que expresa algo de una utilidad sorprendente o descubre un conocimiento nuevo.

A excepción de la poesía, los pioneros siempre dependen de quienes les antecedieron; el presente se apoya en el pasado del mismo modo en que una casa se apoya sobre sus cimientos. El hombre ha llegado mucho más lejos que la naturaleza en la tarea de la creación, y no hubiera podido hacerlo de no haber aceptado ni sentido la existencia de un Dios sin manos ni pies, que sin embargo es capaz de moverse a lo largo y ancho del universo que Él creó y sigue creando con la ayuda del hombre y otros agentes.

Para satisfacer sus deseos, el hombre ya no está limitado a utilizar sólo las manos, ahora cuenta con las maquinas. Tiene el respaldo de una nueva potencialidad, lo que está más allá de la naturaleza. Su vida hoy es mucho más elevada y amplia que nunca, y los niños deben de estar preparados para esta vida. Por ello, el principio fundamental de la educación es la integración de todos estos temas, centralizados en el Plan Cósmico.

\section{El universo ante la imaginación del niño}

María Montessori dice que

(...) para despertar en los niños el interés por el Universo, no debemos brindarles ya desde un comienzo datos aislados, hacerles comprender meramente su 
mecanismo; habrá que transmitirles nociones mucho más elevadas de naturaleza filosófica, adaptadas a la psicología de los niños ${ }^{11}$.

Con ese propósito, puede ser útil contar con la ayuda de algunos mitos o cuentos de hadas, pero sólo aquellos que simbolizan verdades de la Naturaleza, no los que son pura fantasía. La vida es un agente cósmico. ¿Cuál es la mejor manera de presentar esta verdad ante los niños, para apelar a su imaginación?

Es probable que lo que más le llame la atención al niño sean las dimensiones, la tremenda magnitud y alcance de la vida en el planeta, lo cual sería simple porque él ya conoce el poder de los números. Se le pueden brindar cifras, fácilmente obtenibles, sobre la población humana de los distintos países, y luego mencionar la vida en las profundidades del mar, que como se sabe es incalculable.

Primero mencionaremos las ballenas, esos impresionantes gigantes marinas, que al ser tan grandes es lógico que no sean tantos como los peces más chicos. Las ballenas viven en grupos en los mares del norte pero en el invierno se trasladan a regiones más cálidas, donde se unen con otras especies, como la ballena blanca de la Antártida. Allí, no hay cientos de grupos, hay cientos de miles. Dicho esto, no es difícil imaginar el resto de la vida marina, compuesta por miríadas de multitudes de criaturas de menor tamaño.

Para dar una imagen gráfica de esto, podemos recurrir a las cifras, y si no hay datos estadísticos disponibles, considerar las áreas que quedan cubiertas en ciertos mares durante la estación en que los peces se ven obligados a saltar a la superficie. Se ha observado que sólo los que salen del fondo submarino, porque algún factor les impide estar allí, cubren en tales ocasiones más de diez mil hectáreas (...) A los niños les gusta analizar y comprender estas cifras colosales, y se les puede decir que los peces pertenecen a la aristocracia de la vida y que los géneros inferiores son aún más prolíficos, tanto que no alcanzan los números para contarlos.

Es sabido que las medusas suelen invadir a veces la superficie hasta tal punto que los buques más veloces demoran tres días en cruzar por donde ellas están; para alimentarse, semejante cardumen caza con sus tantísimos tentáculos criaturas vivientes muchísimo más numerosas, las cuales existen en una cantidad que parece inagotable.

A fin de tener una idea de cuán numerosos son esos seres microscópicos, cabe destacar que con su fosforescencia son capaces de iluminar kilómetros y kilómetros de un mar tropical, basta el punto de rivalizar con las estrellas que brillan en una noche despejada. Si con la ayuda de un microscopio se observan en una sola gota de agua cientos de organismos vivos diminutos, ¿cuántos de ellos habrá en el inmenso océano? Se ha estimado que uno de los más pequeños de esos seres vivos del mar es capaz de producir un millón de individuos similares a él en diez días.

Es decir, que luego de veinte días, tal vez haya un millón de millones de esta criatura diminuta, iy en un mes el cubo de un millón! (...) En el reino vegetal, las

\footnotetext{
${ }^{11}$ María Montessori, La Educación de las potencialidades humanas, Ámsterdam, Pierson-Publishing Company, 2015, p. p. 21 a 25. (El libro fue publicado originalmente en inglés, en Madrás (India) por la Editorial Kalaskshetra, en 1948).
} 
cifras son aún más difíciles de calcular; en algunos bosques, hay una maleza tan tupida e impenetrable, que hasta los animales tienen que andar sobre las copas de los árboles para procurarse alimento.

La vida es una aventura y está poblada de peligros, tanto en el mar y el aire como en la tierra. Las especies marinas viven bajo la constante amenaza de ser exterminadas por voraces criaturas de mayor tamaño que buscan saciar su hambre, las cuales a su vez son víctimas de otras aún más grandes.

En la tierra, a estos peligros se les suman las hambrunas, inundaciones, erupciones volcánicas y plagas, las cuales se cobran numerosas vidas; pero todo eso queda minimizado ante la destrucción sobrevenida si el agua o el aire dejaran de cumplir su función vital: se aniquilaría toda forma de vida de un solo golpe mortal. Todos los animales cuentan con el instinto de conservación y sus propias armas para defenderse de cualquier otro peligro, de modo que- siempre sobrevivirá una cantidad que garantice la continuidad de la especie, pero no hay criatura que se pueda defender ante la privación de aquellos elementos indispensables.

Además, siempre se ha alertado acerca del peligro que corre la Tierra ante la posibilidad de una colisión con algún cometa o el enfriamiento del Sol, pero se trata de riesgos remotos y secundarios comparados con la catástrofe que sobrevendría si faltaran el aire o el agua. Si bien no siempre presentaron la misma forma que hoy, parecería que estos dos elementos han mantenido constantes su pureza y naturaleza esencial desde los más remotos comienzos de la vida sobre el planeta, sobreviviendo a cambios colosales, cuando se sumergieron continentes enteros y se produjeron mutaciones el equilibrio del mundo.

\section{El "embrión espiritual"}

María Montessori habla del "embrión espiritual" 12 en su libro La mente absorbente del niño. Dice que

(...) el recién nacido debe emprender un trabajo formativo en el campo síquico, que recuerda el que realiza el cuerpo en el periodo embrionario. Tiene un período de vida que ya no es el de embrión físico y tampoco se parece al que presenta el hombre que será más tarde, Este período postnatal, que puede definirse como el "período formativo", es un período de vida embriológica constructiva que hace del niño un embrión espiritual.

De este modo la humanidad tiene dos periodos embrionales: uno prenatal, similar al de los animales, y otro postnatal, exclusivo del hombre. Así se interpreta el fenómeno que distingue al hombre de los animales: la larga infancia. Es en la infancia donde se observa una clara barrera entre los animales y el hombre; con la infancia el hombre se presenta en la tierra como un ser aparte, cuyas funciones no

\footnotetext{
${ }^{12}$ Montessori, La mente absorbente del niño (Ámsterdam: Montessori-Pierson Publishing Company, 2014), 55-56.
} 
son ni la continuación, ni la derivación de las que se manifestaron los animales superiores.

Representa un salto en la vida: la apertura de nuevos destinos. Lo que permite distinguir las especies son sus diferencias, no sus semejanzas. Las especies nuevas deben tener algo nuevo: no pueden ser una simple una simple derivación de las antiguas: se presentan como originales y productivas de caracteres que nunca han existido antes. La obra es original y creativa, y denota un nuevo impulso en la vida.

Así, cuando aparecieron los mamíferos y las aves, aportaron novedades y no copias o adaptaciones de seres precedentes. Las novedades que se manifestaron al desparecer los dinosaurios, fueron en las aves la defensa apasionada de los huevos, la construcción de los nidos, la protección de los recién nacidos, el valor para defenderlos, mientras los reptiles insensibles abandonaban sus huevos.

Y los mamíferos superaron a los pájaros en la protección de la especie: no hicieron nidos, sino que dejaron que los nuevos seres se desarrollaran dentro de su propio cuerpo, preparando su alimentación con su propia sangre. Se trataba, pues, de caracteres nuevos. Y, por ello, el de la especie humana es un carácter nuevo: tiene una doble vida embrional, un nuevo esbozo, y un nuevo destino, respecto de los demás seres. Este es el punto en que debemos detenernos y a partir del cual debemos emprender el estudio de todo el desarrollo del niño y del hombre en su aspecto psíquico.

Si la obra del hombre sobre la tierra está relacionada con su espíritu, con su inteligencia creativa, espíritu e inteligencia deben constituir el soporte de la existencia individual y de todas las funciones del cuerpo. En torno a éste se organiza su comportamiento, y también la fisiología de sus órganos. El hombre entero se desarrolla dentro de un halo espiritual. Actualmente, nosotros los occidentales también empezamos a progresar hacia este concepto particularmente claro en la filosofía hindú: a través de experiencias prácticas, vamos descubriendo perturbaciones fisiológicas que dependen de hechos psíquicos porque el espíritu no se ocupó de dominarlas.

Si el hombre está regido y depende de un "halo espiritual que lo envuelve", y del cual consigue la organización de su comportamiento individual, los primeros cuidados, los que tienen preferencia sobre todos los demás, deberán dirigirse particularmente hacia la vida psíquica del recién nacido, y no sólo hacia la vida física, como aún ocurre en la actualidad.

\section{"Recuerdo a mi abuela pelando patatas"}

Hablando sobre Montessori y la Educación Cósmica conviene traer a colación lo que dice su nieto Mario Montessori $\mathrm{Jr}^{13}$.

\footnotetext{
${ }^{13}$ Mario Jr. Montessori, La educación para el desarrollo humano. Comprendiendo a Montessori (México D.F.: Diana, 1979), 123- 124.
} 
Una de las características más fascinantes de María Montessori era su habilidad para conectar la vida del momento con la vida del distante pasado. Una simple tarea hacía que empezara a esbozar una visión panorámica de la evolución del hombre hasta la época actual, estimulando irresistiblemente la imaginación de quienes la escuchábamos.

La recuerdo pelando patatas y mirándolas con profundidad, como si supiesen revelar algún secreto de gran importancia. Continuaba su tarea, preguntándose en voz alta cómo descubrió el hombre originalmente el valor de la planta de las patatas, en apariencia una semilla con insignificantes florecillas que producían un fruto venenoso.

¿Qué fue lo que le hizo mirar más allá? ¿Por medio de qué truco de la casualidad descubrió que su utilidad para el hombre no yacía en la parte que aparecía sobre la superficie, sino en la parte oculta en la tierra? ¿Cómo aprendió que esta parte no era venenosa, sino comestible? La patata proviene del Nuevo Mundo. ¿Cómo es que fue introducida, adoptada y cultivada a través de Europa occidental?

El modo en que podía hablar de cosas como las patatas lo llevaban a uno inmediatamente hasta un nivel de pensamiento y a una visión más profunda de la realidad, mientras que al mismo tiempo, permanecía inmerso en la vida humana. Era una experiencia única. Estaba conectada a una cualidad especial de su personalidad y a una profundidad de conocimientos fundamental para su éxito. Aunque es posible que no haya hecho la conexión conscientemente, creo que su desarrollo de la Educación Cósmica surgió de esta desusada habilidad para conectar el pasado y el presente a través del pensamiento imaginativo. Como ella mismo lo señaló en su libro "La educación de las potencialidades humanas": La visión imaginativa es completamente diferente de la mera percepción de un objeto, pues es ilimitada. No sólo la imaginación puede viajar a través del espacio infinito, sino también a través del tiempo infinito. Podemos retroceder a épocas pasadas, y tener una visión de la tierra como era, con las criaturas que la habitaban. Para aclarar si un niño ha comprendido, o no, debemos ver si puede formar una visión de ello dentro de la mente, si ha ido más allá del simple entendimiento... El secreto de la buena enseñanza es considerar la inteligencia del niño como un fértil campo en el que pueden sembrarse semillas, para crecer bajo el calor de una flamante imaginación. Por lo tanto, nuestro objetivo no es solamente que el niño entienda, y menos aún forzarlo a memorizar, sino conmover su imaginación para entusiasmarlo hasta lo más profundo de su corazón ${ }^{14}$.

\section{Los niños son los constructores del Hombre}

Finalizada la Segunda Guerra Mundial, después de los campos de exterminio nazis y de los bombardeos de Hirosima y Nagasaki, María Montessori en la introducción de su libro Educar para un nuevo mundo ${ }^{15}$, hará la siguiente reflexión:

\footnotetext{
${ }^{14}$ Montessori, To Educate the Human Potential (Adhyar, India; Kalakshetra, 1948), 14-15.

${ }^{15}$ Montessori, Educar para un nuevo mundo (Ámsterdam: Montessori-Pierson Publishing Company, 2014), $1-3$.
} 
El mundo en que vivimos ha sido devastado y necesita que se le reconstruya. Un elemento fundamental para ello es la educación. Los intelectuales recomiendan una mejora en la educación así como también se recomienda el regreso a la religión. Pero la humanidad todavía no está lista para la evolución tan fervientemente deseada, que consiste en la construcción de una sociedad que viva en paz y armonía y $\sin$ guerras $(\ldots)$

Si la educación continuara con sus viejas fórmulas y se le siguiera considerando como la simple transmisión de conocimientos, el problema se tornaría irresoluble y no habría esperanza de mejorar el mundo. Solo el estudio científico de la personalidad humana nos puede llevar a la salvación y para ello tenemos ante nuestros ojos a una entidad psíquica en los niños, un grupo social gigantesco, una genuina potencia mundial si se le encamina correctamente. Si tiene que llegar ayuda y salvación serán los niños los que la traigan, pues los niños son los constructores del hombre y de la sociedad. El niño está dotado de un poder interior que puede guiarnos a un futuro más iluminado. Ya no se puede concebir la educación como la mera impartición de conocimientos, hay que buscar otros caminos para liberar las potencialidades humanas. (...)

La observación de los primeros dos años de vida ha echado nueva luz sobre las leyes de la construcción psíquica en la infancia que es completamente distinta de la psicología del adulto. Este es el punto de partida de un nuevo camino, en el que no será el maestro el que enseñe al niño, si no el niño el que enseñe al maestro. Tal vez esto parezca una idea absurda, pero queda claramente demostrada cuando se descubre que la mente infantil absorbe el conocimiento y de ese modo se instruye a sí misma. Esto es fácil de probar si se piensa en el aprendizaje de la lengua, toda una proeza intelectual que realizan los niños. (...)

Dentro de cada niño hay un maestro escrupuloso y exigente, que tiene sus tiempos bien establecidos y que ya a los tres años ha producido un ser que, como afirman los psicólogos, aprendió en ese lapso lo que a un adulto le llevaría sesenta años de duro esfuerzo. La observación científica ha establecido que la educación no es lo que el maestro les da a sus alumnos; la educación es un proceso natural que el individuo lleva a cabo espontáneamente y que no es el resultado de oír palabras, sino que se basa en la experiencia que brinda el contacto con el medio ambiente.

\section{La disciplina interior}

Sobre el fenómeno de la disciplina interior del niño ${ }^{16}$, María Montessori escribe en La mente absorbente del niño:

Debemos tener presente, que el fenómeno de la disciplina interior es algo que debe conseguirse y no una cosa preexistente. Nuestro deber es guiar por la vía de la disciplina. La disciplina nacerá cuando el niño haya concentrado su atención

\footnotetext{
${ }^{16}$ Montessori, La mente absorbente del niño, 240-242.
} 
sobre el objeto que lo atrae y que no sólo permite un útil ejercicio sino también el control de error.

Mediante estos ejercicios se crea una maravillosa coordinación de la individualidad infantil, gracias a la cual el niño se tranquiliza, se siente radiante de felicidad, ocupado, se olvida de sí mismo y, en consecuencia, se muestra indiferente a los premios y recompensas materiales. Estos pequeños conquistadores de sí mismos y del mundo que los rodea, de hecho son superhombres, los cuales nos revelan el alma divina que posee el hombre. La feliz tarea de la educadora consiste en mostrar el camino con perfección, proporcionando los medios y eliminando los obstáculos, empezando por lo que ella misma pueda oponer, pues la educadora puede constituir un enorme obstáculo. Si la disciplina fuese algo preexistente, nuestra labor no sería necesaria; el niño poseería un instinto seguro que le haría capaz de superar cualquier dificultad.

El niño de tres años que llega a la escuela es un combatiente a punto de ser vencido por las represiones. Ya ha desarrollado una actitud defensiva que ocultará su naturaleza más profunda. Las energías superiores que podrían conducirlo a una paz disciplinada y a una sabiduría divina están adormecidas. Lo único que permanece en actividad es una personalidad superficial que se agota a sí misma en movimientos descoordinados, en ideas vagas, en un intento de luchar contra las represiones de los adultos o de huir de ellas. Pero sabiduría e inteligencia sólo esperan ser despertadas en el niño. Las represiones han actuado contra él, pero todavía no está todo perdido y fijado en sus desviaciones, y nuestros esfuerzos no serán vanos. La escuela debe proporcionar al espíritu del niño espacio y el privilegio de desarrollarse.

Al mismo tiempo, la maestra debe recordar que las reacciones de defensa y, en general, las características inferiores que ha adquirido el niño, son obstáculos que impiden la apertura de la vida espiritual y que el niño debe liberarse de ellas. Este es "el punto" de partida de la educación. Si el maestro no sabe distinguir el impulso puro de la energía espontánea que nace de un espíritu sereno, su acción no tendrá resultado. El verdadero fundamento de la eficacia del educador consiste en la capacidad de distinguir entre estos dos tipos de actividad, cada uno de los cuales tiene una apariencia de espontaneidad, porque en ambos el niño actúa por su propia voluntad, pero que tienen un significado completamente opuesto. Sólo cuando el educador ha adquirido una capacidad de discriminación, puede convertirse en observador y guía.

\section{La actitud creadora del niño}

María Montessori en El Niño. El secreto de la infancia hablando sobre los periodos sensitivos y la actitud creadora del niño ${ }^{17}$, escribe:

\footnotetext{
${ }^{17}$ Montessori, El Niño. El secreto de la infancia, 75-82.
} 
La sensibilidad del niño pequeñísimo, antes de que se halle animado de instrumentos expresivos, le conduce a una construcción psíquica primitiva, que puede permanecer oculta. Pero este concepto no corresponde a la realidad. Decir esto sería como afirmar que el niño recién nacido ya posee un lenguaje completamente formado en su interior, mientras que los órganos motores de la palabra son todavía incapaces de expresarlo. Lo que existe es la predisposición a construir el lenguaje. Algo parecido ocurre en cuanto a la totalidad del mundo psíquico, del cual el lenguaje es manifestación exterior.

En el niño existe la actitud creadora, la energía potencial para construirse un mundo psíquico a expensas del ambiente. Para nosotros tiene especial interés el reciente descubrimiento de la biología relativo a los llamados periodos sensitivos, estrechamente relacionados con el fenómeno del desarrollo. ¿De qué depende el desarrollo? ¿Cómo crece un ser viviente?. Cuando se habla de desarrollo, de crecimiento, se habla de un hecho que puede comprobarse exteriormente, pero desde hace muy poco tiempo se ha penetrado en algunas particularidades de su mecanismo interno.

En los estudios modernos existen dos factores para profundizar en tales conocimientos: uno, es el estudio de las glándulas de secreción interna, las cuales se refieren al crecimiento físico y se han vulgarizado enseguida por su considerable influencia práctica en el cuidado de los niños. El otro es el de los periodos sensitivos, que permiten abrigar la posibilidad de comprender el crecimiento psíquico. El científico holandés Hugo de Vries descubrió los periodos sensitivos en los animales, pero fuimos nosotros, en nuestras escuelas, quienes hemos encontrado estos periodos sensitivos en el crecimiento infantil, y los hemos utilizado para la educación.

María Montessori piensa que los periodos sensitivos son

(...) sensibilidades que se encuentran en los seres en evolución, es decir, en los estados infantiles, los cuales son pasajeros y se limitan a la adquisición de un carácter determinado. Una vez desarrollado este carácter, cesa la sensibilidad correspondiente. Cada carácter se establece con auxilio de un impulso, de una sensibilidad pasajera.

Por consiguiente el crecimiento no es algo impreciso, una especie de fatalidad hereditaria incluida en los seres; es un trabajo minuciosamente dirigido por los instintos periódicos o pasajeros, que impulsan hacia una actividad determinada, que quizá es distinta de la que caracterizará al individuo adulto (...) Si el niño no ha podido actuar según las directivas de su periodo sensitivo, se habrá perdido la ocasión de una conquista natural, y se habrá perdido para siempre. Durante su desarrollo psíquico el niño realiza conquistas milagrosas; la costumbre de ver esas conquistas ante de nuestros ojos cotidianamente nos convierte en espectadores insensibles.

¿Pero cómo se orienta el niño, venido de la nada, en este mundo tan complicado? ¿Cómo consigue distinguir las cosas y porqué extraño prodigio 
consigue aprender un lenguaje con sus particularidades más minuciosas, sin tener un maestro, sino simplemente viviendo? Viviendo con simplicidad, con alegría, sin fatigarse; mientras que un adulto, para orientarse en un ambiente nuevo, necesita tantas ayudas, y para aprender una lengua debe realizar áridos esfuerzos, sin conseguir nunca la perfección de la lengua materna, que se aprende en la edad infantil.

Un niño aprende las cosas en los periodos sensitivos, que se podrían parangonar a un faro encendido que ilumina interiormente, o bien a un estado eléctrico que da lugar a fenómenos activos. Esta sensibilidad permite al niño ponerse en contacto con el mundo exterior de un modo excepcionalmente intenso. Y entonces todo le resulta fácil, todo es entusiasmo y vida. Cada esfuerzo representa un aumento de poder. Y cuando, en el periodo sensitivo, ya ha adquirido unos conocimientos, sobreviene el torpor de la indiferencia y la fatiga.

Pero cuando algunas de estas pasiones psíquicas se apagan, otras llamas se encienden y así la infancia pasa de conquista en conquista, en una vibración vigorosa continua, que hemos llamado el gozo y la felicidad infantil. Y en esta llama resplandeciente que arde sin consumirse se desarrolla la obra creadora del mundo espiritual del hombre. En cambio, cuando desaparece el periodo sensitivo, las conquistas intelectuales son debidas a una actividad refleja, al esfuerzo de la voluntad, a la fatiga de la búsqueda, y en el torpor de la indiferencia nace el cansancio del trabajo. Aquí reside la diferencia fundamental, esencial, entre la psicología del niño y la del adulto.

Existe, pues, una especial vitalidad interior que explica los milagros de las conquistas naturales del niño. Pero si durante la época sensitiva un obstáculo se opone a su trabajo, el niño sufre un trastorno, o incluso una deformación, y éste es el martirio espiritual que aún desconocemos, pero que casi todos llevamos dentro en forma de estigmas inconscientes.

Hasta ahora, el trabajo del crecimiento, es decir, de la conquista activa de los caracteres, había pasado, inadvertido; pero una larga experiencia nos ha mostrado las reacciones dolorosas y violentas del niño cuando algún obstáculo externo impide su actividad vital. Como ignoramos las causas de estas reacciones, las juzgamos sin causa y las medimos por su resistencia a ceder a nuestras tentativas para calmarlas.

Con el vago término de caprichos denominamos fenómenos que difieren mucho entre sí. Capricho es todo aquello que carece de causa aparente, todo aquello que puede considerarse como una acción ilógica e indomable. Sin embargo, observamos que algunos caprichos denotan una existencia de causas permanentes que continúan actuando y a las que, evidentemente, no hemos encontrado remedio.

Pero los periodos sensitivos nos pueden aclarar muchos caprichos infantiles; no todos pues existen diversas causas de luchas internas, y además muchos caprichos ya son la consecuencia de desviaciones de la normalidad que aún se agravan más con un tratamiento erróneo. Pero los caprichos relacionados con los conflictos internos que tienen lugar durante los periodos sensitivos son tan pasajeros como el periodo sensitivo mismo, y no dejan huellas en el carácter. 
No obstante, comportan la grave consecuencia de obstaculizar el desarrollo, lo cual es irreparable en el futuro desarrollo de la vida psíquica. Los caprichos del periodo sensitivo son expresiones externas de necesidades insatisfechas, toques de alarma de una condición equivocada, de un peligro, y si se ha presentado la posibilidad de comprenderlos y satisfacerlos, desaparecen inmediatamente.

Entonces se observa cómo al estado de agitación sigue un estado de calma. En cambio, ese estado de agitación hubiera podido asumir finalmente la forma de enfermedad. Por tanto, es necesario buscar la causa de cada manifestación infantil, que nosotros denominamos caprichosa, precisamente porque esta causa se nos escapa, cuando podría representar en cambio una guía para penetrar en los rincones misteriosos del alma infantil, y preparar un periodo de comprensión y de paz en nuestras relaciones con el niño (...)

El desarrollo psíquico no viene porque sí, y no tiene sus estimulantes en el mundo exterior. Es guiado por las sensibilidades pasajeras constituyendo instintos temporales que presiden la adquisición de los caracteres diversos. Y aunque esto se produce a expensas del ambiente exterior, éste no tiene importancia constructiva alguna, ya que ofrece únicamente los medios necesarios a la vida, paralelamente a lo que ocurre con la vida del cuerpo que recibe del ambiente sus elementos vitales por la respiración.

Son las sensibilidades interiores que guían en la elección de lo necesario en el ambiente multiforme y en las situaciones favorables a su desarrollo. ¿Cómo guían? Guían convirtiendo sensible al niño ricamente para ciertas cosas e indiferente para otras. Cuando se encuentra en un periodo sensitivo, es como si emanara del mismo, una luz divina que iluminara únicamente ciertos objetos sin iluminar los demás, y en aquéllos se concentra el universo, para él. Pero no se trata sencillamente de un deseo intenso de encontrarse en ciertas situaciones, de no absorber más que determinados elementos; existe en el niño una facultad especialísima, única, y es la de aprovechar estos periodos para su crecimiento.

Es durante los periodos sensitivos que efectúa sus adquisiciones psíquicas, como por ejemplo, la de orientarse en el ambiente exterior; o también, es capaz de animar de manera más perfecta e íntima sus instrumentos motores. En estas relaciones sensitivas entre el niño y el ambiente está la llave que puede abrirnos el fondo misterioso en el que el embrión espiritual desarrolla el milagro de su crecimiento.

\section{Los años vitales para el desarrollo humano}

Al nacer, existe en el niño la potencialidad de crear su mente ${ }^{18}$. Es a través de la interacción con su medio ambiente, que llegará a comprenderse y a descubrir su lugar en el universo. En "La mente absorbente del niño", María Montessori se adentra en el periodo embrionario del niño recién nacido, periodo en el que se organiza la mente. Parte de algunas proposiciones basadas en la biología; del desarrollo embrional del niño; de la ley

\footnotetext{
${ }^{18}$ Montessori, La mente absorbente del niño, 15-20.
} 
natural que lo predispone a un comportamiento libre; y del gran misterio de la gestación espiritual de la persona humana. Es lo que denomina "los años vitales". Un tiempo que tiene una importancia decisiva en el desarrollo humano.

$\mathrm{Y}$ en este sentido, sabemos que los dos primeros años de vida abren un nuevo horizonte. Revelan un nuevo horizonte, revelan leyes de construcción psíquica, que habían sido ignoradas hasta que en 1947, María Montessori las formuló en la India. Se pueden resumir diciendo que "el niño mismo nos ha ofrecido el don de esta revelación; nos ha hecho conocer un tipo de psicología,- la suya -, completamente v distinta de la del adulto".

$\mathrm{Y}$ es que, el niño tiene una mente capaz de absorber, -María Montessori la llama "la mente absorbente"-, capaz de absorber conocimientos y el poder de instruirse a sí mismo. Por eso son tan importantes los primeros años de la vida, y por eso es tan importante el Método Montessori que en estas primeras edades se dirige, sobre todo, a potenciar las extraordinarias capacidades de crecimiento del niño.

Por ejemplo, en relación con el lenguaje, María Montessori dice que

(...) en lo más íntimo de cada niño existe, por así decirlo, "un maestro vigilante". Un "maestro interior" que es capaz de obtener los máximos resultados de todos y cada uno de los niños, sea cual sea su familia, o el país en que se hallen. El único lenguaje que el hombre adquiere con perfección y sin titubeos es el que aprende en el primer periodo de la infancia.

Cuando nadie puede impartir ninguna enseñanza al niño. Y sucederá que cuando se haga grande, si debe aprender una nueva lengua, ninguna ayuda podrá hacer que llegue hablar esta segunda lengua con la misma perfección con que habla la lengua que aprendió en la primera infancia.

Si se reflexiona sobre este hecho, vemos que cada vez resulta más evidente que la obra de "construcción" realizada en este periodo por el niño es impresionante, y que todo lo que poseemos en la edad adulta ha sido construido por el niño que fuimos durante nuestros dos primeros años. A los tres años el niño ya ha establecido los cimientos de la personalidad humana, y entonces necesita la ayuda particular de la educación escolar. Las conquistas realizadas por él son tales que se puede afirmare que el niño que entra en la escuela a los tres años, ya es un hombre en virtud de las conquistas realizadas con anterioridad. María Montessori dice que

(...) si comparamos nuestra habilidad de adultos con la del niño, precisaríamos sesenta años de duro trabajo para conseguir lo que el niño ha logrado en los primeros años. Podemos decir que el niño a los tres años ya es un hombre, aunque sabemos que esta singular facultad del niño para absorber el ambiente aún no se ha agotado completamente en este periodo inicial. La Educación no es lo que el maestro imparte, sino un proceso natural que se desarrolla espontáneamente en el 
individuo humano; la educación no se adquiere escuchando palabras, sino a través de experiencias efectuadas en el ambiente. Entonces cabe preguntarse: ¿cuál es la función del maestro en estas edades?

\section{María Montessori afirma que}

(...) la función del maestro no es hablar, sino preparar y disponer una serie de motivos de actividad cultural en un ambiente especialmente preparado. Mis experiencias en países diversos han durado más de cuarenta años. Y a medida que los niños crecían los padres me pedían que continuara la educación de los niños ya mayores. De ese modo descubrimos que la actividad individual es la facultad que estimula y produce por sí sola el desarrollo. Y que esto vale tanto para los pequeños en edad preescolar como para los niños de primaria y de los niveles más avanzados. Por ello sostengo que cualquier reforma de la educación debe basarse en el desarrollo de la personalidad humana. El hombre mismo debería convertirse en el centro de la educación.

Y algo muy importante:

El hombre no se desarrolla cuando llegamos a la universidad, sino que inicia su desarrollo mental a partir del nacimiento, y lo efectúa con la mayor intensidad en los primeros tres años de vida. Por eso creo que es necesario prestar mucha más atención a este periodo decisivo que a cualquier otro. Así el niño se nos revelará como la más grande maravilla de la naturaleza. Entonces no nos enfrentaremos con el niño considerado como un ser sin fuerza, casi como un recipiente vacío que debemos llenar con nuestra sabiduría, sino que su dignidad se alzará ante nuestros ojos a medida que lo consideremos el constructor de nuestra inteligencia, el ser, que trabaja infatigablemente con alegría y felicidad, siguiendo un programa preciso, para construir esta maravilla de la naturaleza que es el Hombre.

La primera infancia es una etapa decisiva: son los años vitales para el desarrollo humano, por eso es tan importante.

\section{Los sentimientos y las emociones}

María Montessori escribe sobre el tema de los sentimientos y las emociones ${ }^{19}$ en su libro La educación de las potencialidades humanas:

Últimamente, siguiendo al psicoanálisis, se ha hablado mucho de la sublimación de los instintos. Para lograr este objetivo, las maestras han incentivado los sentimientos y emociones, pero los escolares no mostraron ninguna reacción

\footnotetext{
${ }^{19}$ Montessori, La educación de las potencialidades humanas, 32.
} 
satisfactoria. Los psicólogos basan sus teorías en la conducta de los animales y la respuesta de los adultos al psicoanálisis; solo se nos unen en lo tocante al tema de una reforma en la educación, pero en este tema ya hemos recorrido gran parte del camino, ipartiendo directamente del niño! Ellos buscan un método educativo que se adapte a sus teorías y nosotros buscamos una teoría psicológica que se adapte a nuestro método.

Para ejemplificar esta sublimación de los instintos, se puede citar a un escritor moderno, quien afirmo con acierto que la ciencia moderna es un monumento a la curiosidad sublimada. Estamos totalmente de acuerdo, y hemos probado que cuando se le da al niño una visión detallada de cómo comenzó la vida y como progresó hasta el presente, se despierta en él un gran interés por la ciencia y todas sus maravillas.

El instinto de curiosidad del niño es sublimado por esos intereses elevados, pero tal cosa solo es posible si se los presenta ante el niño a una edad mucho más temprana de la que los psicólogos estiman aceptable. El niño nos ha enseñado que esta etapa temprana es el único momento de su vida en que su sensibilidad e interés son más profundos de lo que lo será después, y que cuando sea mayor sólo podrá estudiar científicamente y con precisión si ya está dotado de una emoción y sentimiento profundos por esos temas. Entonces no será simple curiosidad lo que lo mueva, sino un intenso interés, un entusiasmo basado en la emoción.

\section{Un planeta donde no hay escuelas}

En La mente absorbente del niño utiliza una comparación de una dimensión planetaria $^{20}$ para describir el modo de aprender del niño:

Si yo os dijera que existe un planeta donde no hay escuelas, ni maestros, sin ninguna necesidad de estudiar, y donde, viviendo y paseando, sin más fatiga, los habitantes llegan a conocerlo todo y a fijar sólidamente todo el saber en su cerebro, ¿no os parecería una hermosa fábula? Pues bien, esto, que parece tan fantástico y suena a invención de una fértil imaginación, es un hecho, una realidad; porque éste es el modo de aprender del niño inconscientemente. Éste es el camino que sigue. Lo aprende todo inconscientemente, pasando poco a poco del inconsciente a la conciencia, avanzando por un sendero en que todo es alegría y amor.

\section{Inmóvil frente al telescopio}

En El método de la pedagogía científica aplicado a la educación de la infancia otro de sus libros fundamentales, repasando la experiencia vivida en la "Casa dei Bambini", fundada por María Montessori en el popular barrio romano de San Lorenzo, el 6 de enero de 1907, habla de la observación cientifica, ${ }^{21}$ una de las claves distintivas del Método Montessori:

\footnotetext{
${ }^{20}$ Montessori, La mente absorbente, 44.

${ }^{21}$ Montessori, El método de la pedagogía científica aplicado a la educación de la infancia, 148.
} 
Cuando tuve que preparar para este sistema maestras no ejercitadas en la observación científica, pude medir la distancia que lo separa de los sistemas empleados en las escuelas tradicionales.

Las mismas maestras inteligentes que han comprendido los principios, encuentran muchas dificultades cuando se trata de ponerlos en práctica. No pueden comprender que tienen que adoptar una actitud pasiva como la del astrónomo que se sienta inmóvil frente al telescopio, mientras los astros ruedan vertiginosamente por el espacio.

Esta idea de que la vida y todas las cosas se desenvuelven por sí solas y que para estudiarlas, para descubrir sus secretos, o dirigirlas, es preciso antes conocerlas sin intervenir, es muy difícil de ser verdaderamente asimilada y ponerla en práctica. La maestra ha aprendido demasiado a ser la única actividad libre de la escuela; le parece que su obligación consiste en sofocar la libre actividad de sus alumnos. Cuando no puede obtener el orden y el silencio, se siente avergonzada y mira a su alrededor como si quisiera hallar un testimonio de su inocencia. Es en vano que se le haya enseñado que el desorden de los primeros días es inevitable. Cuando se apercibe de que no puede hacer otra cosa sino mirar, se pregunta si no sería mejor presentar su dimisión, ya que no ejerce de maestra.

Después, cuando empieza a pensar cuáles son los actos que debe impedir y cuáles debe tan sólo observar, la maestra antigua experimenta una fuerte emoción y empieza a preguntar si podrá mantenerse a la altura de su nueva misión. La maestra que no esté preparada se encontrará durante mucho tiempo desorientada e impotente; mientras que la que esté preparada quedará tanto más maravillada y será mayor su interés, cuanto más vasta sea su cultura científica y su práctica en la experimentación.

\section{Un verdadero milagro de la creación}

El hombre que llega al mundo bajo la forma de niño se desarrolla rápidamente por un verdadero milagro de creación. El recién nacido no tiene todavía ni el lenguaje ni los otros caracteres relativos a las costumbres de la estirpe: no tiene inteligencia, ni memoria, ni voluntad, ni el poder de moverse y de tenerse en pie; y sin embargo este recién nacido lleva a cabo una auténtica creación psíquica. A la edad de dos años habla, camina, reconoce las cosas. Y, pasados los cinco años, alcanza el desarrollo psíquico suficiente para ser admitido a estudiar en las escuelas $^{22}$.

\section{La serenidad del que se siente feliz}

En su libro El método de la Pedagogía científica. Aplicado a la educación de la infancia $^{23}$, escribe María Montessori:

\footnotetext{
${ }^{22}$ Montessori, La formación del hombre, 13-14.

${ }^{23}$ Montessori, El método de la Pedagogía científica, 356-357.
} 
Se creía equivocadamente que la educación de los pequeños debía de ser puramente física, olvidando que el espíritu también pugna por vivir y desarrollarse, y que la vida espiritual es al fin y al cabo lo que domina en la existencia en todas las edades. Por eso nuestro método toma, como punto de partida, el desarrollo psíquico espontáneo del niño y le ayuda en su crecimiento, con procedimientos suministrados por la observación y la experiencia. Si la cultura física conduce al niño a gozar de la salud del cuerpo, la cultura intelectual y moral, le conducen a los nobles goces del espíritu y lo llevan de sorpresa en sorpresa a realizar descubrimientos, tanto en el ambiente externo como en la misma intimidad de su alma. Estos son los goces que verdaderamente contribuyen a formar un hombre, y los únicos que educan a la infancia de un modo digno de ella.

Nuestros niños son muy distintos de todos los que llenan las escuelas. Tienen la serenidad del que se siente feliz y la desenvoltura del que se siente dueño de sí mismo (...) La "Casa dei Bambini" parece ejercer una influencia espiritual sobre todo el mundo. Yo he visto a duros hombres de negocios,- agobiados por un exceso de trabajo y de preocupaciones-, serenarse y perder su rígida tensión, ante un espectáculo del alma humana que se desarrolla de un modo natural delante de ellos: ven niños prodigiosos y niños felices. La infancia de una humanidad más avanzada y noble.

El poeta británico William Wordsworth, que fue un gran enamorado de la Naturaleza, empezó a sentir la misteriosa voz de sus colores y de sus silencios, y le preguntó cuál era el secreto de la vida. Y un día tuvo una revelación: el secreto de la Naturaleza está en el alma del niño. Él nos descubre la síntesis de la verdadera vida que reside en el espíritu de la humanidad. Pero ese espíritu que "envuelve nuestra infancia", es luego oscurecido por las sombras de las cárceles en las que se encierra al niño a medida que crece. El hombre ve morir al Niño en la lejanía, y desvanecerse, huyendo, en el frío contacto de sus ocupaciones cotidianas. Nuestra vida social es a menudo el oscurecimiento y la muerte natural que se instala en nosotros. Nuestro método tiende a preservar y a mantener el fuego espiritual de los hombres y a salvar su verdadera naturaleza, frente a los deprimentes yugos de la sociedad.

\section{Atisbos de inmortalidad}

Aunque mis ojos ya no puedan ver ese puro destello que en mi juventud me deslumbraba, aunque nada pueda hacer volver la hora del esplendor en la hierba, de la gloria en las flores, no debemos afligirnos, pues hallaremos ánimo en el recuerdo: en aquella primera amistad, que habiendo sido una vez, será por siempre; en los condolientes sentimientos que brotaron de los pesares humanos; en la fe que traspasa la muerte; en los años, que dan la serenidad.

\section{"Me gustaría ser joven"}

Con 82 años de edad, unos días antes de su muerte María Montessori declaraba:

"Me gustaría ser joven, para trabajar más, para tener más tiempo de escribir y de pensar 
nuevas ideas, y especialmente mi libro sobre "La Mente del hombre". Pero, aunque estaba llena de vida, no tuvo tiempo de concluirlo. Falleció el 6 de mayo de 1952.

\section{Un llamamiento a todos los niños del mundo}

Cuando planeaba un viaje a África para dar varias conferencias invitada por el Presidente de Ghana, fallece a los 82 años, el 6 de mayo de 1952, en la ciudad de Noordwijck am See (Holanda), en cuyo cementerio está enterrada. En su lápida se puede leer la siguiente frase: "Io prego I cari bambini che possono tutto, di unirse a me per la costruzione della pace negli uomini en el mondo". ("Pido a todos los queridos niños, que tanto poder tienen, que se unan a mí para la construcción de la paz entre los hombres de todo el mundo") ${ }^{24}$.

\section{Ciudadana del mundo}

En el cementerio romano del Verano, donde están enterrados sus padres, María Montessori es recordada con la siguiente inscripción:

María Montessori, Chiaravalle, provincia de Ancona (Italia) 31 de agosto Noordwijk 6 de mayo de 1952. Ilustre científica y pedagoga que dedicó toda su vida a la renovación y el progreso espiritual de la humanidad a través del niño. Descansa en el cementerio católico de Noordwijk (Holanda), lejos de su tierra que tan profundamente había amado, lejos de sus seres queridos aquí enterrados. Así quiso ella testificar la universalidad de su obra que la hizo ciudadana del mundo ${ }^{25}$.

\footnotetext{
${ }^{24}$ Montessori, An Anthology, 57.

${ }^{25}$ Montessori, An Anthology, 57.
} 


\section{Perfil biográfico de María Montessori}

\section{0}

María Montessori nace el 31 de agosto de 1870 en Chiaravalle, provincia de Ancona (Italia).

\section{5}

Con sus padres se traslada a Roma.

\section{3}

Se inscribe en la "Scuola Tecnica Michelangelo Buonarroti" de Roma, reservada tradicionalmente a los "chicos" que quieren estudiar ciencias.

\section{6}

Aunque quiere estudiar ingeniería, se siente atraída por la biología. Y finalmente se inclina por la medicina.

\section{3}

Obtiene la licenciatura en Ciencias Naturales, lo que le permite matricularse en tercero de Medicina (el 12 de febrero de 1893). Montessori siempre había tenido una gran pasión por la Medicina por su dimensión humanística y social. Quería dedicarse a los más pobre y a los enfermos.

Asignaturas como Fisiología, Antropología e Higiene le hicieron muy sensible a la injusticia social. Una cuestión que condicionaría toda su vida. También muy importante fueron las clases de Clínica Psiquiátrica del profesor ${ }^{26}$, Clodomiro Bongfigli, que como María Montessori provenía de la región de la Marche. Se sintió tan atraída por esta especialidad, que se decidió por esta disciplina a la hora de hacer su tesis doctoral

\section{6}

El 10 de julio de 1896 obtiene el título de Doctor en Medicina y Cirugía por la "Regia Universita degli Studi di Roma", realizando una tesis titulada: "Contributo clinico allo studio delle allucinazioni a contenuto antagonistico", dirigida por el profesor Ezio Sciamanna, director de la Clinica Psichiatrica dell'Università di Roma. Montessori es a menudo descrita como la primera mujer médico en Italia, pero antes que ella, se graduó en medicina Ernestina Papel, en el Instituto di Studi Superiori de la Universidad de Florencia en el año 1877, ejerciendo con una consulta propia dedicada a las enfermedades ginecológicas y de la infancia.

\footnotetext{
${ }^{26}$ Montessori, El método de la pedagogía científica aplicado a la educación de la infancia, 148.
} 
María Montessori fue precedida en el Ateneo romano por Edvige Benigni en $1890 \mathrm{y}$ por Marcellina Corio Viola, en 1890. Pero, la noticia de su doctorado fue publicada en algunos periódicos romanos como el «Messaggero» e «Il Don Chisciotte», destacando que en 1896 de 21.813 matriculados en todas las universidades italianas sólo 132 eran mujeres. En 1986 María Montessori forma parte de una delegación italiana que asiste al "Congreso para los Derechos de la Mujer” que se celebra en Berlín. Especializada en Neurología se dedica a la medicina durante diez años, hasta descubrir una nueva vía que la llevará a la pedagogía.

Después de un año de servicio en el Ospedale San Giovanni, y tres años en la Clínica psichiatrica de la Universidad de Roma, el 20 de enero de 1900 se inscribió en un curso de postgrado sobre "Cuidados sanitarios" (Polizia Sanitaria), obteniendo el diploma el diploma de "Ufficiale Sanitario", el 3 marzo 1900. Luego viajó a París para estudiar en la Universidad de la Sorbona, donde dirigida por el profesor Bourneville profundizó en los trabajos de Itard y Séguin. Su primer trabajo académico, titulado "Sul significato dei cristalli del Leyden nell'asma bronchiale”, fue publicado en el Bollettino della Società Lancisana degli Ospedali di Roma XVI (1896).

\section{7}

En 1897 con S. De Sanctis, publicó "Sulle cosiddette allucinazioni antagonistiche", en Policlinico IV, (1897): 118-119. Ese mismo año, con Giuseppe Montesano (futuro padre de su hijo Mario), publicó "Ricerche batteriologiche sul liquido cefalo rachidiano dei dementi paralitici”, Roma, F.1li Capaccini, 1897, stratto dalla Rivista quindicinale di Psicologia, Psichiatria, Neurologia (1897): 1-13.

\section{8}

En el invierno de 1898 se trasladó a Londres por invitación del ministerio de Educación para estudiar el tema de las escuelas para niños con deficiencia mental. A su regreso a Italia, en 1899, es invitada a pronunciar una conferencia sobre psicología y pedagogía especial destinada a tipo de niños. Y después el ministerio le encarga la creación Scuole Normali di Roma.

El tema de los niños "anormales" y la promoción del "Istituti speciali medicopedagogici”, era una de las cuestiones que más interesaban a la joven doctora. En virtud de su gran interés por la educación de los niños deficientes, el Ministro (que había sido su maestro en la Universidad) Guido Baccelli la nombra directora de la Scuola Magistrale Ortofrenica, con la ayuda de Giuseppe Montesano.

$\mathrm{Su}$ trabajo en esta Scuola estuvo estrechamente realacionado con la creación, en 1899, de la «Lega Nazionale per la protezione dei fanciulli deficienti», que presidía Clodomiro Bonfigli entonces director del "Ospedale Santa María della Pietà" de Roma. 
María Montessori enseñaba en esta Scuola algunas de las lecciones que había dado el año anterior en la Scuole Normali di Roma, pensadas para la preparación de las futuras maestras. En la Scuola tenía una clase "piloto" en la que trabajaba con los materiales creados por Séguin, para bambini anormali. Experimentando estos materiales y creando otros nuevos. Pero a pesar del gran trabajo realizado por María Montessori y Giuseppe Montesano, la Scuola Ortofrenica, no había sido reconocida por el Gobierno.

Pero, tanto la «Lega», como el profesor Bonfigli, entonces diputado en el Parlamento y presidente della "Lega", trabajaron para la aprobación de una ley sobre asistencia pasiquiatrica y el Istituti medico-pedagogici. Y probablemente gracias a estos apoyos la Scuola Magistrale Ortofrenica pudo ser inaugurada oficialmente el 7 de abril 1900 guiada por Montesano y Montessori, la cual enseñaba la asignatura de Higiene.

A continuación se abrió, in via dei Volsci el "Istituto medico-pedagogico", con cincuenta niños recuperados del manicomio de Roma. d allora ricoverati nel manicomio romano. La inauguración de "Istituto" tuvo lugar el 24 de abril de 1900, en un acto al que acudieron muchas mujeres de la aristocracia romana que más tarde ayudarían a María Montessori en la creación de la Casa dei Bambini.

El 31 de marzo de 1898 nace su hijo Mario (su padre es el psiquiatra Giusepe Montesano). María Montessori participa como médico en el "II Congreso Pedagógico Italiano" que se celebra en la ciudad de Turín, presentando una comunicación en la que planteaba la institución de clases especiales e institutos médico-pedagógicos para la atención de niños con problemas ${ }^{27}$. Pronuncia diversas conferencias en Roma.

\section{9}

En octubre de 1899, se le asigna una cátedra de "pedagogia pei deficienti" en la Scuola di Alto Magistero femminile. Y es nombrada consejera de la Liga nacional para la protección de los niños subnormales. Participa en un Congreso internacional de mujeres que se celebra en Londres. Ingresa en la sección europea de la Sociedad Teosófica.

\section{0}

Se crea la Scuola Magistrale Ortofrenica. En esta institución Montessori, junto a Giuseppe Montesano, forman a los futuros maestros. La estrecha colaboración con el profesor Montesano se acaba una vez que nace su hijo Mario. Mario llevará el apellido de su padre (Montesano) pero el médico no se casará con María Montessori. Montessori empezará a investigar sobre las dificultades que sufren los "niños normales" en las escuelas

\footnotetext{
27 "Norme per una classificazione dei deficienti in rapporto ai metodi speciali di educazione", en Atti del Comitato Ordinatore del II Congresso Pedagogico Italiano 1899-1901 (Napoli: Trani, 1902), 144-167, y en Vita dell'Infanzia XI, no. 9 (1962): 3-12.
} 
tradicionales. Ello le conducirá a realizar los estudios de Filosofía y Psicología. Escribe L’Antropologia pedagogica, que será publicada, en 1903, en Milán.

\section{1}

En 1901, Montessori presentó en Nápoles, en el segundo Congresso Pedagogico Nazionale, una comunicación titulada Norme per una classificazione dei deficienti in rapporto ai metodi speciali di educazione. En este trabajo expone las ideas de Séguin, ampliándolas con una serie de planteamientos propios que ella define como un sistema de educación que denomina «método fisiológico». Montessori afirma que el valor científico de la obra de Séguin destinado a "l'educazione degl'idioti", ponía de manifiesto la existencia de dos problemas: la falta a nivel científico de experimentación de este método, y a nivel pedagógico la carencia de una actuación adecuada de profilaxis social.

\section{3}

Después de la experiencia de la Scuola Magistrale Ortofrenica, decide estudiar en la Facultad de Filosofía de la Universidad de Roma. El 16 de julio de 1903 se matricula en tercero de Filosofía. En ese año Montessori publica el libro titulado "L'Antropologia Pedagogica” dedicado a “Onorevole Luigi Credaro, professore di pedagogia nell'Università di Roma".

\section{4}

El 14 de enero de 1904 María Montessori solicita al Rector de la Universidad de Roma poder matricularse en cuarto de Filosofía, lo que se le concede "per 1'anno scolastico 19031904". Ese curso asiste a las clases de "Psicologia con el profesor Sante De Sanctis, Storia di Roma nel Medioevo con el profesor Giuseppe Tomassetti, Antropometria con el profesor Ugo Vram, y Magisterio con el profesor Luigi Credaro”. Las clases de Antropometría con el profesor Vram, le servirán para avanzar en su preparación técnica.

El profesor Vram, era un miembro distinguido de la Sociedad romana de Antropología, junto con los profesores Moschen y Sergi. Esta Sociedad admitirá a María Montessori, el 22 de febrero de 1903 como socia honorario. E1 29 diciembre 1904, es nombrada profesora de Antropología, en la Universidad de Roma, que ejerce hasta 1916. Tiene 34 años de edad ${ }^{28}$.

\footnotetext{
${ }^{28}$ Montessori publicará el artículo: L'Antropologia pedagogica, Milano, Antonio Vallardi, 1903, y en Vita dell'Infanzia a. XLVI, no. 8 (1997): 8-15. También: Sui caratteri antropometrici in relazione alle gerarchie intellettuali dei fanciulli nelle scuole, in «Archivio per 1'Antropologia e l'Etnologia», vol. XXXIV, fasc. 2, 1904, pp. 243-300. Y la Influenza delle condizioni di famiglia sul livello intellettuale degli scolari. Ricerche d'igiene e antropologia pedagogiche in rapporto all'educazione, Rivista di filosofia e scienze affini II, no. 3-4 e 5-6 (settembre-ottobre 1904): 234-284.
} 


\section{5}

El trabajo de investigación presentado por Montessori para obtener la cátedra es publicado en 1905, con il titulo de I caratteri fisici delle giovani donne del Lazio, Roma, Società Romna di Antropologia, 1905 estratto dagli «Atti della Società Romana di Antropologia», vol. XII, fasc. I, pp. 3-86. También publica Lezioni di antropologia pedagogica, Regia Università di Roma, anno 1905-1906, Litogr. Sabbadini. Un trabajo académico importantísimo para su biografía que no siempre ha sido resaltado en algunas bibliografías de María Montessori.

\section{6}

Un interés persistente en Montessori fue su atención por la profesionalidad de los maestros. Un interés que se acentúa durante la enseñanza de la Antropologia pedagogica, y cuando es nombrada miembro del Consiglio direttivo della Scuola Pedagogica di Roma, el 5 abril de 1906. Puesto que conservará hasta 1910.

\section{7}

El 6 de enero, inaugura la primera "Casa dei Bambini" del Instituto Romano de Bienes Inmuebles (Instituto Romano di Beni Stabili, IRBS) en la vía dei Marsi, 58, en el barrio romano de San Lorenzo. Montessori publica L'importanza della etnologia regionale nell'antropologia pedagogica, in «Ricerche di Psichiatria e Nevrologia, Antropologia e Filosofia», dedicate al professor Enrico Morselli nel XXV anno del suo insegnamento universitario, Milano, Vallardi, (1907): 603-619.

\section{8}

Apertura de varias "Case dei Bambini" de la Sociedad Humanitaria de Milán. Inauguración de la "Casa dei Bambini" de vía Giusti del generalato de las Franciscanas Misioneras de María (FMM). Las Franciscanas favorecen la creación de otras "Case de Bambini" en Roma.

\section{9}

El barón y la baronesa Alice Franchetti invitan a María Montessori a sus escuelas populares de Città di Castello en Perugia. Y promueven la publicación de la obra de Montessori: Il metodo della pedagogia scientifica applicato all'autoeducazione infantile nella Casa dei bambini, obra editada más tarde varias veces $(1913,1935$, hasta la IV, de 1950, aparecida con el título La scoperta del bambino) y pronto traducida a las principales lenguas. La traducción al español es del pedagogo Juan Palau. El Método es publicado en España, en 1915, con el título: El Método de la Pedagogía científica, aplicado a la educación de la infancia en la Casa dei Bambini. Alice Franchetti favorece la difusión internacional del 
Método de María Montessori. El primer artículo internacional sobre esta notable experiencia Montessoriana se publica el 1 de septiembre de 1909 en Londres, escrito por Maude G. May en el Journal of Education. Posteriormente se publicarán también varios artículos en revistas norteamericanas.

\section{0}

El Ayuntamiento de Roma crea dos nuevas "Case dei Bambini". Una en el Pincio y otra en el barrio judío, cerca de la Iglesia de Sant'Angelo in Pescheria. En este mismo año se publica su obra siguiente, L'autoeducazione nelle scuole elementari (Turín, 1910), también reeditada dos veces en 1916 y en 1940, aplica el método a las enseñanzas en la escuela elemental.

\section{2}

Se publica la primera traducción estadounidense del Método Montessori. Se celebra en Roma el I Curso Internacional Montessori.

\section{3}

Primer viaje de María Montessori a Estados Unidos. Alexander Graham Bell y su hija invitan a María Montessori a visitar Norteamérica. Abren la primera "Casa dei bambini" de los Estados Unidos. Enseguida se extiende el movimiento montessoriano y se forma la American Montessori Association que encabezaron el mismo Alexander G. Bell y su esposa Margaret Wilson, hija del presidente Wilson. Ruptura con las experiencias llevadas a cabo por el Instituto Romano di Beni Stabili (IRBS) y las Franciscanas Misioneras de María (FMM)

\section{4}

Se publica un manual de divulgación del Método en Estados Unidos (Montessori's Own Handbook) ${ }^{29}$. María Montessori dirige en Roma el "II Internacional Training Course".

\section{5}

Segundo viaje a Estados Unidos. En la Exposición Universal de San Francisco, celebrada para conmemorar el 50 aniversario del Canal de Panamá, María Montessori instala un aula

\footnotetext{
${ }^{29}$ El extraordinario éxito de Montessori en Norteamérica se interrumpe de golpe, cuando William Kilpatrick, prestigioso profesor de la Columbia University, escribe el libro The Montessori System Examined, en el que descalifica muy duramente el Método Montessori. Tendrán que transcurrir más de 30 años, para que el movimiento montessoriano vuelva a extenderse en los Estados Unidos, para convertirse en la actualidad en uno de los representantes más prestigiosos de la renovación pedagógica y de la educación infantil de calidad. Nancy McCormick Rambusch reimplantó el Método Montessori en Norteamérica, estableciendo la Sociedad Americana Montessori (American Montessori Society) en 1960.
} 
con paredes de cristal para que el público pueda ver cómo trabajaba un grupo de cuarenta niños de tres a seis años. ${ }^{30}$ Pronuncia varias conferencias y dirige varios cursos en California y en Los Ángeles. Apertura de la Casa de los Niños en la Casa de la Maternitat i Expòsits de Barcelona, y en varios colegios de los Padres Vicencianos.

\section{6}

Crea en Barcelona el "Seminari-Laboratori de Pedagogía", del que es nombrada su primera directora. De 1916 a 1918 divide su tiempo entre Estados Unidos y Barcelona.

\section{7}

Tercer viaje a los Estados Unidos para asistir a la boda de su hijo Mario con Helen Christy, en la ciudad de San Francisco.

\section{8}

El 21 de diciembre recibe la Bendición Apostólica del Papa Benedicto XV que califica muy positivamente el libro Il Metodo della Pedagogía Scientifica applicato all'educazione infantile nelle Case dei Bambini ${ }^{31}$.

\section{9}

María Montessori dirige en Londres el "First Internacional Course in England". Posteriormente, de 1920 a 1930 dirigirá diversos cursos en Austria, Alemania, Holanda e Italia.

\section{0}

El 23 de enero, el Rector de la "The University of Ámsterdam” preside la ceremonia académica en la que se recibe a María Montessori como Profesora de la citada Universidad y se reconoce el alto valor científico del Método Montessori.

\footnotetext{
${ }^{30}$ Como decimos, el 23 de octubre de 1915 María Montessori instaló en la Exposición Internacional de San Francisco (USA), un aula de paredes de cristal en la que trabajaban 30 niños de tres a seis años, de distintos países, con la idea de dar a conocer el Método Montessori a nivel mundial. Cien años después, la Opera Nazionale Montessori, -que este año celebra el 90 aniversario de su creación en Roma-, ha instalado en la EXPO de Milán, una gran Aula Montessori, con imágenes de las Escuelas Montessori italianas y de la Casa dei Bambini de Zhengzhou (China), para poner en evidencia la dimensión internacional del movimiento montessoriano y su perenne actualidad de un Método Pedagógico que comenzó hace más un siglo.

${ }^{31}$ El Papa Benedicto XV le entrega una carta en la que se lee: "La benedizione apostolica che impartiamo alla dilecta figlia María Montessori sia pegno di quelle grazie e di quei celesti favori che auguriamo per rendere fecondo di bene Il Metodo della Pedagogía Scientifica applicato all'educazione infantile nelle Case dei Bambini. Dal Vaticano, 21 novembre 1918. Benedictus S. S. XV'
} 


\section{3}

Montessori dirige en Londres un nuevo curso. María Montessori se plantea la extensión de su metodología a los niños y niñas de 3 a 6; 6 a 9; y 9 a 12 años de edad. Es nombrada Doctor Honoris Causa por la "Universidad de Dirham" (Holanda). Funda en Roma la Opera Nazionale Montessori.

\section{7}

Se crea en Buenos Aires la "Sociedad Argentina Montessoriana". Invitada a visitar el país, pronuncia conferencias en Buenos Aires, La Plata y Córdoba.

\section{8}

"La Societat Montessori de Barcelona" organiza en esta ciudad el "XVIII Curso Internacional Montessori".

\section{9}

Se celebra un "Congreso Internacional Montessori" en Dinamarca. María Montessori funda la "Association Montessori Internationale", cuya sede está en Ámsterdam.

\section{0}

Preside en el Capitol de Roma un Congreso Internacional en cuya inauguración interviene el Príncipe Buoncompagni, gobernador de Roma, y el senador Giovanni Gentile, ministro de Educación.

\section{1}

Gandhi pronuncia una conferencia en el "Montessori Training College" de Londres, el 28 de Octubre.

\section{2}

La policía política fascista abre un dossier contra María Montessori y su Método. Y es espiada por los agentes de la OVRA.

\section{3}

Ruptura con las autoridades fascistas italianas. Exilio.

\section{4}

Viaja a Dublín donde es recibida por Eamon de Valera, Primer Ministro de Irlanda. Dirige el IV Congreso Internacional Montessori que se celebra en Roma, en un clima de gran tensión y bajo la estrecha vigilancia de la policía política y de los agentes de la OVRA. En 
el Congreso participa Jean Piaget que es Presidente de la Asociación Montessori en Suiza. Se prohíben las Case dei Bambini y si clausura la Opera Nazionale Montessori. Se ve obligada a exiliarse. Es evidente que una pedagogía basada en el desarrollo de la libertad personal de los niños no puede desarrollarse en un sistema totalitario como la Italia de Benito Mussolini.

\section{6}

Refugiada en España abandona el país unos meses antes del golpe militar de 18 de Julio. Viaja a Londres. Allí preside el "V International Montessori Congreso" que se celebra en Oxford.

\section{7}

Preside la ceremonia de entrega de diplomas de la primera promoción de un curso para maestras Montessori impartido en Laren (Holanda).

\section{9}

Viaja a la India con su hijo Mario para impartir un curso en Adyar, Madrás (Chennai), invitada por la "The Theosophical Society".

\section{0}

Le sorprende el estallido de la Segunda Guerra Mundial en la India. A pesar de su nacionalidad italiana, país "aliado" de la Alemania nazi, "enemigo" de Gran Bretaña, podrá continuar su tarea educativa, pero su hijo Mario, que la acompaña, será internado en un campo de concentración. Como regalo de cumpleaños (cumple 70 años) el Virrey de la India le anuncia la puesta en libertad de su hijo.

\section{3}

La The Theosophical Publishing House, de Adyar, Madrás (India) publica la primera versión de su obra Educazione e Pace, luego editada en su forma definitiva en 1949.

\section{6}

Regresa a Holanda donde se instala con su familia. Dirige un curso en Londres. El The Educacional Institute of Scotland of Edinburgh le concede el título de profesora honorífica (Honorary Fellowship).

\section{7}

Emprende un segundo viaje a la India que dura dos años, invitada por la The Indian Montessori Society para impartir varios cursos. Allí se dan los primeros pasos para la 
creación de la primera "Montessori University de la India". María Montessori amplía su teoría pedagógica y evolutiva para los niños de 0 a tres años. $\mathrm{Y}$ escribe varios libros fundamentales. Vuelve a Italia y el Parlamento italiano le rinde homenaje por su extraordinaria aportación educativa. Gobierno la invita a abrir nuevos colegios Montessori en diversas ciudades de su país, y se refunda la Opera Nazionale Montessori, que sigue en Roma llena de actividad en la actualidad.

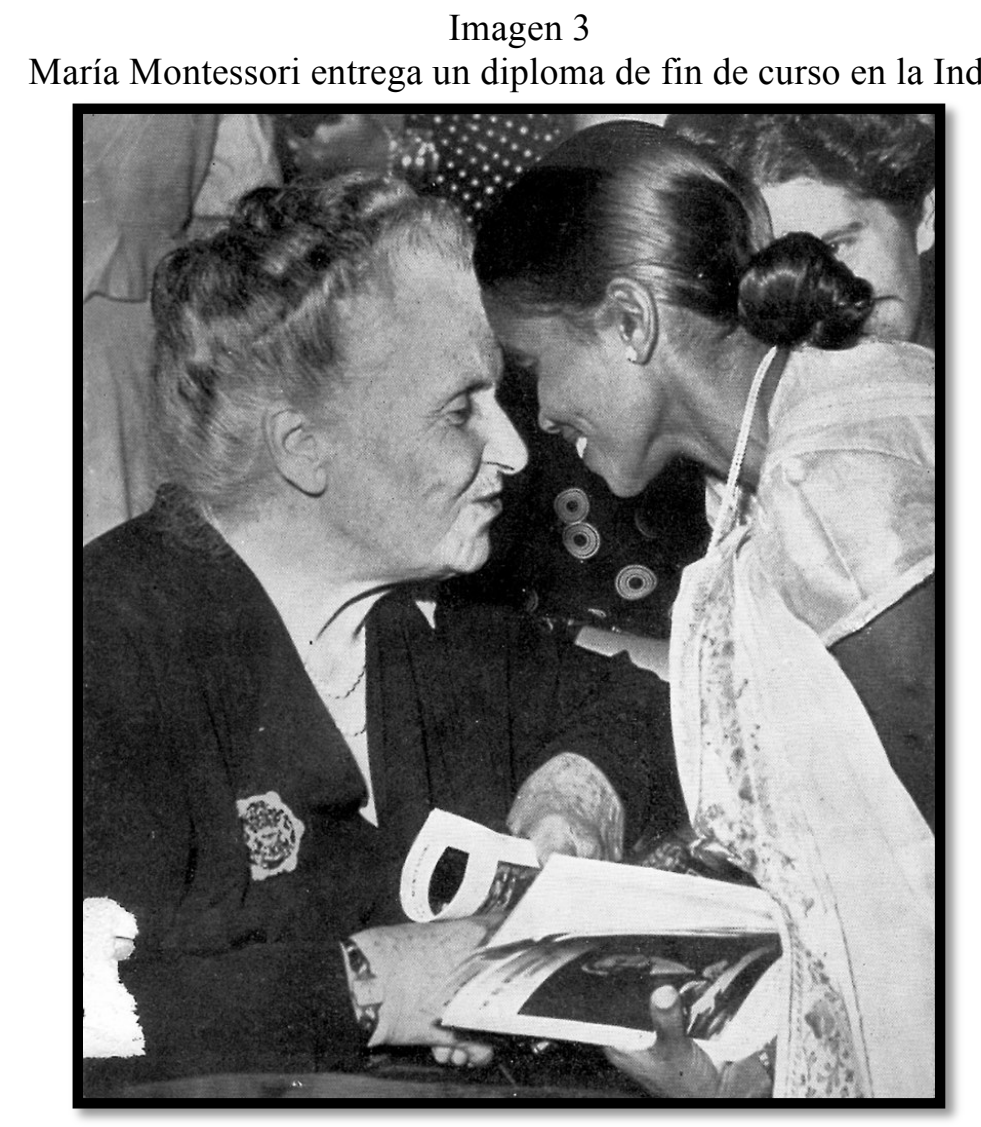

Fuente: Archivo de la Sociedad Teosófica en Adyar, India.

\section{8}

Imparte un curso en Colombo, capital de Sri Lanka. Allí se publica su libro Wat You Should Know about Your Child. Revisa su obra El Método Montessori, cuya reedición llevará el nuevo título de The Discovery of the Child. 
Imagen 4

María Montessori, s. f.

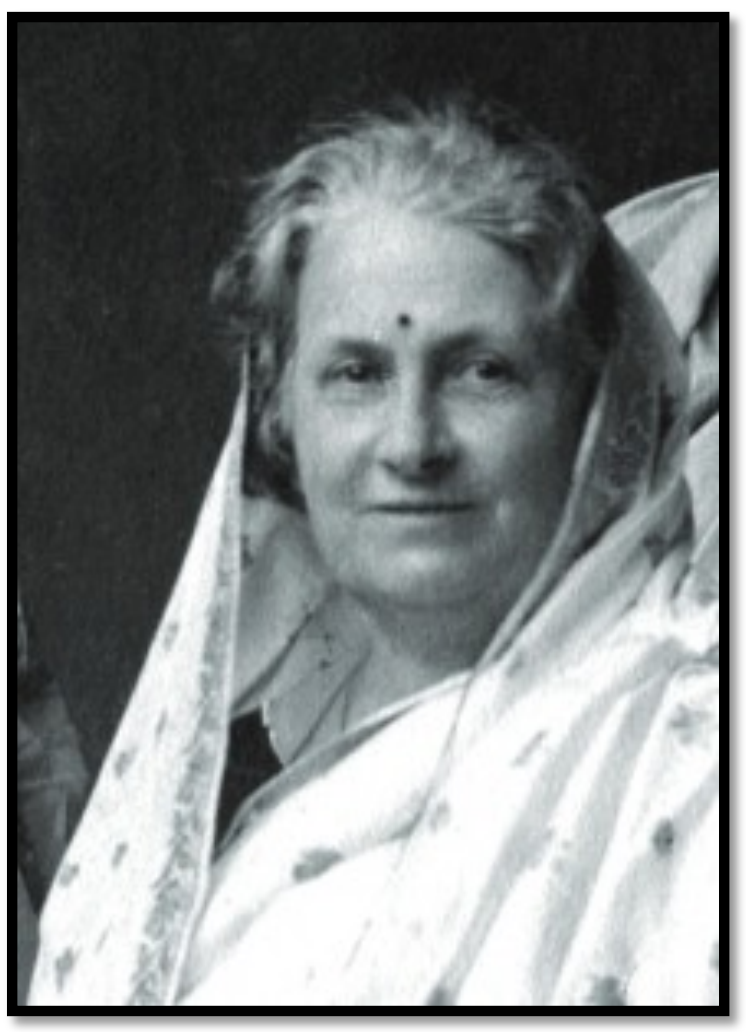

Fuente: Archivo de la Sociedad Teosófica en Adyar, India.

\section{9}

Se publica en Madrás (India) The Absorbent Mind (La mente absorbente del niño). La Independencia de la India produce la creación de dos países: India y Pakistán. María Montessori decide abandonar la India, después de presidir un curso que se celebra en Karachi, capital de Pakistán. Montessori, preside el "Congreso Internacional Montessori" que se celebra en San Remo. Los anteriores se celebraron en Helsinki, Niza, Ámsterdam, Roma, Oxford, Copenhague, Edimburgo y Londres.

\section{0}

Pronuncia varias conferencias en diversas ciudades de Escandinavia, en Oslo y Noruega. Con ocasión del tercer aniversario de la Declaración Universal de los Derechos Humanos, María Montessori es invitada por la UNESCO a pronunciar una conferencia en las Sesión Plenaria de esta organización internacional que se celebra en Florencia, el 31 de octubre, que titula "El ciudadano olvidado". Es nombrada Doctor Honoris Causa por "The University of Ámsterdam". Y ciudadana de honor de la ciudad de Chiaravalle, donde nació en 1870. Es nominada al Premio Nobel de la Paz. 


\section{1}

Celebra su 81 aniversario pronunciando una conferencia en la Universidad de Imsbrück (Austria). Por tercera vez es nominada para el Premio Nobel de la Paz. María Montessori preside el IX Congreso Internacional que se celebra en Londres.

\section{2}

Cuando estaba planeando un viaje a África para dar varias conferencias invitada por el Presidente de Ghana, falleció el 6 de mayo de 1952, en la ciudad de Noordwijck am See (Holanda), en cuyo cementerio está enterrada. En su lápida se puede leer la siguiente frase, que es todo un formidable programa: "Io prego I cari bambini che possono tutto di unirse a me per la costruzione della pace negli uomini en el mondo". ("Pido a todos los queridos niños, que tanto poder tienen, que se unan a mí para la construcción de la paz entre los hombres de todo el mundo").

\section{Imagen 5}

Tumba de María Montessori (1870-1952)

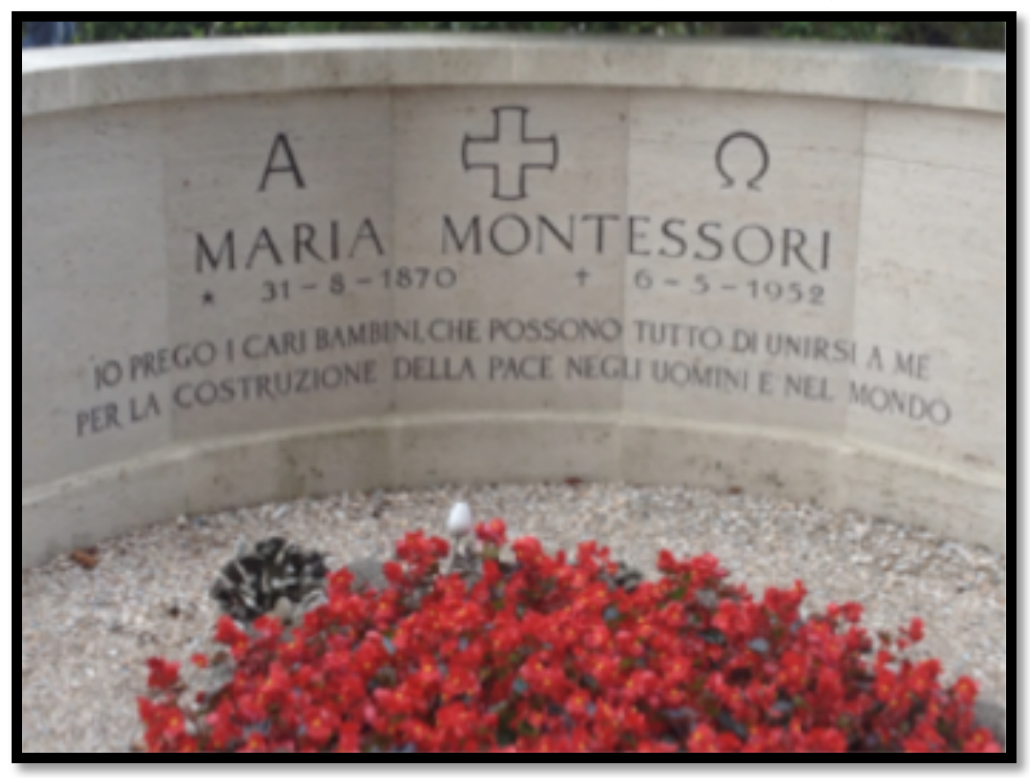

Fuente: Fotografía del personal de este artículo. 


\section{Bibliografía}

\section{Algunos libros de María Montessori}

Montessori, María. The Discovery of the Child. Madras: Kalakshetra, 1948.

Montessori, María. Education for a New World. Madras: Kalakshetra, 1948.

Montessori, María. To Educate the Human Potential. Madras: Kalakshetra, 1948.

Montessori, María. What You Should Know about Your Child. Colombo (Sri Lanka):

Bennet \& Company, 1948.

Montessori, María. Educazione e pace. Milano: Garzanti, 1949.

Montessori, María. The Formation of Man. Madras: Kalakshetra, 1955.

Montessori, María. The Absorbent Mind. Madras: Kalakshetra, 1967.

Montessori, María. The Secret of Childhood. Hyderabad: Orient Longman, 1971.

Montessori, María. Dall'infanzia all'adolescenza. Milano: Garzanti, 1994 (I edición original en francés con el título: De l'enfant à l'adolescent, 1948; I edición italiana Garzanti, 1949).

Montessori, María. The 1946 London Lectures. Amsterdam: Montessori-Pierson Publishing Company, 2012.

\section{Libros y artículos sobre María Montessori}

Cives, Giacomo. "María Montessori tra scienza, spiritualità e laicità". Studi sulla formazione 2 (2014): 119-147.

Foschi, Renato. María Montessori. Roma: Ediesse, 2012.

Grazzini, Camilo. Cosmic Education at the Elementary Level and the Role of the Materials (2004). Disponible en http://www.montessori-ami.org/

Hayes, Mary. Montessori's View of Cosmic Education. 25th International Montessori Congress Papers, 1-9, 2005.

Kramer, Rita. María Montessori: A biography. Nueva York: Da Capo Press, 1976.

Lillard, Paula P. Montessori. The Science behind the Genius. New York: Oxford University Press, 2005.

María Montessori: A Centenary Authology (1870-1970). Amsterdam: Association Montessori Internationale, 1970.

“María Montessori e il XXI secolo". Atti del Congresso Internazionale, Chiaravalle 16-1718 novembre 2000, edizioni Opera Nazionale Montessori.

Montessori, Mario. The Human Tendencies and Montessori Education. Amsterdam: Association Montessori Internationale, 1966.

Montessori, Mario Jr. La educación para el desarrollo humano, Comprendiendo a Montessori. México D. F.: Diana, 1979. 
Montessori, Renilde. World Odyssey-Revelations of the Possible. Association Montessori Internationale, 1-5, 2005.

Morales Ruiz, Juan José y Luis Jorge García Dueñas. María Montessori. Madrid: Ed. Fundación Emmanuel Mounier, 2009.

Obregón, Nora. “Quién fue María Montessori”. Contribuciones desde Costepec 10 (enerojunio, 2006).

Pema, Jetsun. The Tibetan Children's Villages. 25th International Montessori Congress Papers, 1-8, 2005.

Sanchidrián Blanco, Carmen. María Montessori: El Método de la Pedagogía científica: aplicado a la educación de la infancia. Madrid: Biblioteca Nueva. (Edición y estudio introductorio de Carmen Sanchidrián Blanco), 2003.

Schwegman, Marjan. María Montessori. Bologna: Il Mulino, 1999.

Standing, E. Mortimer. María Montessori: her life and work. Fresno, California, The New American Library of World Literature, 1962.

Sullivan Smith, Monica. The Montessori "Secret" (2004). Disponible en http://www.montessoriami.org/

Trabalzini, Paola. María Montessori: da Il metodo a la scoperta del bambino. Roma: Artacne, 2003.

Yaglis, Dimitrios. Montessori. México D. F.: Editorial Trillas, 1996. 